\title{
The Long-run Effects of War: A Literature Review
}

Nguyen K. Hang, Le T. Trang, Hoang T. T. Huong, Nguyen T. Huong, Le Kien, Nguyen D. Khoi

\begin{abstract}
We review the literature for the long-term effects of war on human capital. We document the negative effects of exposure to war on individual health, prospective earnings, educational attainment, prospective earnings, and labor productivity in the long run. The findings call for immediate and effective actions to reduce the detrimental repercussions of war in both the short run and long run.
\end{abstract}

\section{Introduction}

Conflicts have disastrous consequences for a country, including death, displacement, damage of physical capital and public infrastructure, and a halt in economic growth. According to evidence from macro-level studies, the economy will swiftly recover. On the other hand, the direct and indirect effects of these events on human dimensions may be more long-term and disastrous than the physical ones. On the one hand, conflicts can have a direct impact on families, resulting in the death of loved ones, changes in family structure, and resource depletion. On the other hand, the physical destruction generated by these battles may have long-term implications for survivors.

Children may be disproportionately disadvantaged by the destruction of physical capital and deterioration of economic means among survivors, given the age-specific character of many human capital expenditures. War, for example, can interrupt children's education by destroying schools, eliminating instructors, and changing family structures and household income. Famines, famine, infectious disease outbreaks, post-war trauma, and health infrastructure devastation can 
all have a negative impact on children's health. Physical capital deterioration may have long-term ramifications for children through their future labor market performance, given the welldocumented empirical evidence on the relationship between human capital and earnings.

\section{Method}

The evidence regarding the long-term impact of conflicts on human development was examined in this study. The Web of Science database was searched from January 1, 2000, until the date of the search. The purpose of our review was to compile previously published information on the long-term effects of conflict. As search terms, various variations of "long-run impacts" and "armed conflict" were employed. Additional studies were discovered by searching by hand. To conduct screening and full-text reviews for all papers, the authors used Covidence, an electronic organizing tool for systematic reviews. The study population, the location of a past or contemporary armed conflict or an area, and the study population's exposure to the armed conflict were all taken into account. Studies on mental and behavioral health were only considered if they also provided data on physical health or child development.

The risk of bias was assessed at the study outcome levels for each unique study based on the data source, study population, sampling procedure, data collection and analysis methodologies, and any particular characteristics of the population. Studies whose methodology was questioned or defective were excluded. Due to the difficulty in obtaining data in conflict settings, research from single facilities, studies using only facility-based data, and case reports were included. From studies that met the inclusion criteria, data on the time period, study country and sub-region, identified conflict, study design, reference population, type of exposure, health outcomes, access to basic needs, mortality, and associations between exposures and outcomes were extracted onto a 
data extraction form. Where available, data on protective and mitigating factors on child health outcomes was abstracted. When missing data was discovered, authors were contacted as soon as possible. In the event of conflicts or questions, the reviewers came to an agreement.

\section{Results and Discussion}

According to Davis and Weinstein (2002), the Allied bombardment of Japanese cities during World War II was one of the most severe shocks to relative city sizes the world has ever witnessed. They discover that in the aftermath of the accident, there was an exceptionally strong recovery. Most cities returned to their relative position in the distribution of city sizes after about fifteen years. The random growth theory, which assumes no reversion to the previous path, is especially prone to this. According to the growing returns theory, the distribution of city sizes appears to be highly resilient to transient shocks of any scale in practice, no matter how appealing the theoretical promise of spatial catastrophes may be. Finally, the return to the former growth path appears to provide solid evidence for the locational basics argument.

Brakman, Garretsen, and Schramm (2004) study whether a big transitory shock has an influence on German city growth and size distribution using a one-of-a-kind data set. Based on recent work by Davis and Weinstein (2001) on Japan, they offer the strategic bombardment of German cities during WWII as an example of such a shock. The goal of this study is to examine the impact of this shock on German city growth and the resulting size distribution. If city growth follows a random course, the war shock had a long-term impact on German urbanization. If the random walk hypothesis is not proven, as the second set of hypotheses predicts, it will imply that the war shock had only a brief effect on the city-building process. The researchers discovered that city growth in 
western Germany did not follow a predictable pattern, although it did in eastern Germany. Different postwar economic regimes are most likely to blame for this outcome.

Miguel and Roland (2005) investigate the long-term impact of US bombing on Vietnam's economy. The most comprehensive bombing campaign in military history, as well as massive humanitarian implications, defined the Vietnam War. Using a unique US military dataset that includes bombing intensity at the district level $(\mathrm{N}=584)$, they assess whether the war's damage resulted in persisting local poverty traps. They compare the heavily battered districts to other districts using an instrumental variable technique, controlling for district demographic and geographic variables and relying on the distance to the 17 th parallel demilitarized zone. The US bombing had no significant consequences on poverty rates, consumption levels, infrastructure, literacy, or population density in the area until 2002. According to this study, even the most intensive bombing in human history did not result in local poverty traps in Vietnam.

Angrist and Kugler (2008) study the impact of an exogenous rise in coca leaf pricing and cultivation in Colombia, where the majority of coca leaf is now gathered. This transition resulted in slight economic gains in rural areas, most notably increased self-employment incomes and an increase in the labor supply of teenage boys. As a result of increased coca production, rural areas became significantly more violent, whereas urban areas remained mainly untouched. These findings back with the hypothesis that the Colombian civil war is driven by the financial opportunities offered by coca, and that soldiers' rent-seeking limits the economic benefits of coca.

Shemyakina (2006) uses inequalities in spatial and temporal exposure to the 1992-1998 armed conflict in Tajikistan to study the influence of violent conflict on educational achievement. Data on past damage to a household's houses from the 1999 Tajik Living Standards Survey, as well as data on incidents during the conflict, are used within a conceptual framework that compensates for 
important individual, household, and community characteristics. Girls who were in school throughout the crisis and lived in conflict-affected areas were less likely than girls of the same age who lived in conflict-free areas to complete their required education. The data also reveal that being exposed to violent conflict has a large and statistically significant negative influence on girls enrolling in school. Exposure to regional and home conflict had little effect on the schooling of boys. Community and household fixed effects, violent selection, and migration have no effect on the results.

According to Le and Nguyen (2020), the Allied bombing of Vietnam, which was the world's longest and most powerful aerial bombardment, had a negative impact on school-age pupils' scholastic achievement and subsequent labor market outcomes. Using a difference-in-differences framework to exploit the plausible exogenous district-by-cohort variation in bomb destruction, they find that an increase in bomb intensity leads to significantly fewer educational years completed and lower future earnings for school-age children exposed to the bombardment. They also suggest that the long-term repercussions of aerial bombing could be driven by both supplyside (inadequate school security and a teacher shortage) and demand-side (residential casualties, limited access to healthcare, damaged buildings, and increased reliance on welfare assistance) variables. The findings highlight the importance of conflict prevention and post-conflict reconstruction in accomplishing long-term development objectives.

According to Ichino \& Winter-Ebmer (2004), children in Austria and Germany who were 10 years old at the time of the war, or who were more directly involved through their parents, received less education than children in non-war countries like Switzerland and Sweden. They also show that these individuals lost a large amount of money 40 years after the conflict, which can be attributed 
to educational losses suffered as a result of the war. The economic impact is evaluated in terms of lost gross domestic product.

Le (2021) investigates the influence of armed violence on the weight of young children in the Democratic Republic of the Congo. They use a difference-in-differences paradigm to detect deleterious effects of conflict exposure on child weight by using variance in armed conflict exposure across districts and within-district variation in the timing of whether the kid was exposed to armed conflict due to birth timing. When children are exposed to armed conflict, they weigh 0.20 and 0.24 standard deviations less for their age and height, respectively. Armed conflict increases the chances of children being underweight or wasting by 4.7 and 2.7 percentage points, respectively. According to their heterogeneity research, children from disadvantaged backgrounds, such as those born to low-educated mothers, poor mothers, and rural mothers, are disproportionately affected.

Le \& Nguyen (2020) investigate the hidden but continuous impact of conflict on birth weight outcomes in 53 developing countries that have suffered violence in the last three decades (19902018). Despite differences in districts and conception months-years, they find that intrauterine exposure to armed conflict in the first trimester of pregnancy reduces a child's weight at delivery by 2.8 percent and increases the frequency of low birth weight by 3.2 percentage points. Infants born to low-income and illiterate moms are more vulnerable to armed conflict's detrimental effects. 